\title{
Clinical Pharmacists: Essential During a Poison Outbreak
}

\author{
Joanne C. Routsolias ${ }^{1}$ (D) $\cdot$ Renee Petzel Gimbar ${ }^{2} \cdot$ Michele Zell-Kanter $^{3}$ \\ Received: 21 May 2020 / Revised: 10 June 2020 / Accepted: 11 June 2020 / Published online: 7 July 2020 \\ (C) American College of Medical Toxicology 2020
}

Emergency medicine (EM) pharmacy services began in the USA in the 1970s [1-3]. Support for training and expansion of EM pharmacy services has significantly increased over the past 15 years, and these services are now available in the majority of US healthcare institutions [3]. The role of EM clinical pharmacists is multifaceted. They are essential in providing expertise in pharmaceutical care and heighten the level of medication safety for a variety of Emergency Department (ED) patients [4, 5]. To be successful, the EM pharmacist must possess a vast clinical acumen in critical care, medicine, and ambulatory care.

In recent years, medication shortages on a local or national level have added to the complexity of caring for patients in hospitals and outpatient settings [6]. Reasons for shortages may include cost, supply chain interruption, or unexpected toxicologic and infectious outbreaks. The American College of Medical Toxicology (ACMT) recently issued important position statements about the potential impact on patient care and the healthcare system when crucial antidotal therapy and prescription drugs are not available [6,7]. These ACMT position statements emphasized how shortages compromise the quality of patient care, threaten patient safety, and create a heavy financial burden on all parties involved $[6,7]$. Clinical pharmacists possess the expertise to devise alternative pharmaceutical solutions when established treatments are not available. They help ensure patient safety and optimize patient care while limiting additional cost [5-7].

Supervising Editor: Mark B. Mycyk, MD

Joanne C. Routsolias

joanne.routsolias@cookcountyhhs.org

1 Department of Emergency Medicine and Pharmacy, Cook County Health, 1950 West Polk Street, 7th Floor, Chicago, IL 60612, USA

2 Department of Pharmacy Practice, UIC College of Pharmacy, 833 S. Wood Street, Suite 164, Chicago, IL 60612, USA

3 Department of Emergency Medicine, Cook County Health, 1950 West Polk Street, 7th Floor, Chicago, IL 60612, USA
Our involvement in an outbreak of patients poisoned with long-acting anticoagulant rodenticide-tainted synthetic cannabinoids (LAAR-SC) in the Chicago area will illustrate the essential value of clinical pharmacists. In March 2018 patients presented to multiple local EDs with abnormal bleeding. This local outbreak quickly became a large regional outbreak involving many different public health agencies. Medical toxicologists and EM clinical pharmacists from the Toxikon Consortium at Cook County Health, the University of Illinois Hospital, and the Illinois Poison Center were involved in the management of 178 coagulopathic patients [8]. The Toxikon Consortium is a multidisciplinary collaboration of all toxicology resources and experts from these institutions. As EM clinical pharmacists, we were included in both the EM and Medical Toxicology bedside services at our own institutions. In the early stages of this outbreak we were faced with antidotal shortages (vitamin $\mathrm{K}_{1}$ ), antidotal formulation issues, and the uncertainty of how long to treat this coagulopathic patient population. These patients were otherwise healthy and did not feel any untoward effects of being coagulopathic, making medication compliance challenging. The majority of patients were indigent and did not have reliable transportation or insurance coverage. We were concerned about patients being compliant with their scheduled follow-up appointments.

The Medical Toxicology team met daily to make and adjust recommendations for reversal of bleeding due to a LAAR-SC. We initially treated patients with intravenous vitamin $\mathrm{K}_{1}$ until the patient was able to tolerate an oral regimen that required them to take 30 tablets a day. It soon became apparent that the supply of 1-mg and 5-mg oral vitamin $\mathrm{K}_{1}$ tablets would be depleted. A single 50-mg dose would require the patient to ingest 10 tablets. At the time of this outbreak, there was only a single manufacturer of the oral vitamin $\mathrm{K}_{1}$ tablets. EM clinical pharmacists anticipated the potential oral vitamin $K_{1}$ shortages and notified the Medical Toxicology physicians who were coordinating patient care.

We needed to develop an alternative vitamin $\mathrm{K}_{1}$ treatment plan. Since oral $\mathrm{N}$-acetylcysteine has been safely administered IV for the treatment of acetaminophen toxicity [9-11], we 
entertained the possibility of administering IV vitamin $K_{1}$ orally [12]. Undiluted injectable vitamin $K_{1}$ is stable for 30 days refrigerated and at room temperature [12-14]. We recommended using a filtered needle for vitamin $\mathrm{K}_{1}$ withdrawal from the ampule and to use orange juice to mask its unpleasant taste [12-14]. By implementing this strategy, we were able to prevent depletion of our institution's oral vitamin $\mathrm{K}_{1}$ supplies, reduce inpatient costs since IV vitamin $\mathrm{K}_{1}$ was less expensive than oral vitamin $\mathrm{K}_{1}$, and increase compliance among our patients by decreasing pill burden. In the interim, we replenished our outpatient vitamin $K_{1}$ through donated governmental supplies in order to provide patients with sufficient oral vitamin $\mathrm{K}_{1}$ upon discharge. As a result of clinical pharmacist input, patients tolerated the treatment course and their coagulopathies reversed. Some patients continued to be followed for more than 3 months with no untoward sequelae.

As clinical pharmacists working in the ED and as members of the Medical Toxicology team, we made critically important treatment recommendations for LAAR-SCpoisoned patients during this large scale outbreak. Our pharmacy training and experience allowed us to contribute to both the pharmacologic and workflow challenges to optimize patient care. Clinical pharmacists understand both inpatient and outpatient pharmacy departments and the pharmaceutical supply chain. Clinical pharmacists are trained to devise alternative therapeutic modalities to ensure that patients receive appropriate treatment while hospitalized and upon discharge.

Adequate antidotal supplies are critical in managing outbreaks as in our LAAR-SC outbreak, where resource allocation became a daily priority. This is only one example of the invaluable role the clinical pharmacist played in an outbreak, in the ED, and as part of a multidisciplinary toxicology team. Clinical pharmacists are leaders, problem-solvers, and productive collaborators who provide expertise in pharmaceutical care. Clinical pharmacists serve as educators to all members of the healthcare community concerning pharmaceutical needs during outbreaks. Clinical pharmacists assist in policymaking both locally and nationally and collaborate with other agencies to manage large public health outbreaks. Clinical pharmacists are key stakeholders when providing care at the bedside. We should be included and recognized as essential members of the healthcare team for routine patient management and when designing or coordinating larger efforts.

Sources of Funding No grant funding was received for this work.

\section{Compliance with Ethical Standards}

Conflict of Interest None.

\section{References}

1. Thomasset KB, Faris R. Survey of pharmacy services provision in the emergency department. Am J Health-Syst Pharm. 2003;60: 1561-4.

2. Rm E, Waeckerle JF, McNabney WK. The clinical pharmacist in the emergency medicine. Am J Hosp Pharm. 1977;34:843-6.

3. Rudis MI, Attwood RJ. Emergency medicine pharmacy practice. J Pharm Pract. 2011;24(2):135-45.

4. Morgan SR, Acquisto NM, Coralic Z, Basalyga V, Campbell M, Kelly JJ, et al. Clinical pharmacy services in the emergency department. Am J Emerg Med. 2018;36:1727-32.

5. Farmer BM, Hayes BD, Rao R, Farrell N, Nelson L. The role of clinical pharmacists in the emergency department. J Med Toxicol. 2018;14:114-6.

6. Mazer-Amirshahi M, Stolbach A, Nelson LS. ACMT position statement: addressing the rising cost of prescription antidotes. J Med Toxicol. 2018;14:168-71.

7. Mazer-Amirshahi M, Fox ER, Nelson LS, Smith SW, Stolbach AI. ACMT position statement on prescription drug shortages. J Med Toxicol. 2020;16(3). https://doi.org/10.1007/s13181-020-00775-7

8. Devgun JM, Rasin A, Kim T, Mycyk MB, et al. An outbreak of severe coagulopathy from synthetic cannabinoids tainted with longacting anticoagulant rodenticides. Clin Toxicol (Phila). 2019. https://doi.org/10.1080/15563650.2019.1690149 .

9. Acetylcysteine Solution. USP [package insert]. American Reagent, Inc: Shirley; 2011.

10. Hendrickson RG, Howland M. N-Acetylcysteine. In: Nelson LS, Howland M, Lewin NA, Smith SW, Goldfrank LR, Hoffman RS, editors. Goldfrank's Toxicologic Emergencies, 11e. New York: McGraw-Hill. http://accessemeregencymedicine.mhmedical.com/ content .aspx ?bookid $=2569 \&$ sectionid $=21026$ 1914. Accessed May 10, 2020.

11. Smilkstein MJ, Knapp GL, Kulig KW, Rumack BH. Efficacy of Oral $\mathrm{N}$-acetylcysteine in the treatment of acetaminophen overdose. N Engl J Med. 1988;319:1557-62.

12. Afanasjeva J. Administration of injectable vitamin K orally. Hosp Pharm. 2017;52:645-9.

13. Crowther MA, Donovan D, Harrison L, McGinnis J, Ginsberg J. Low-dose oral vitamin $\mathrm{K}$ reliably reverses over-anticoagulation due to warfarin. Thromb Haemost. 1998;79:1116-8.

14. Wilson SE, Watson HG, Crowther MA. Low-dose oral vitamin K therapy for the management of asymptomatic patients with elevated international normalized ratios: a brief review. Can Med Assoc J. 2004;170:821-4.

Publisher's Note Springer Nature remains neutral with regard to jurisdictional claims in published maps and institutional affiliations. 